\title{
Reflexôes sobre o adoecer e mudanças dietéticas durante a assistência nutricional em pacientes com hepatite $\mathrm{C}$
}

I ${ }^{1}$ Carla Magalhães Costa Lima, ${ }^{2}$ Rosângela Passos de Jesus, ${ }^{3}$ Maria do Carmo Soares de Freitas, ${ }^{4}$ Lucivalda Pereira Magalhães de Oliveira I

Resumo: Trata-se de investigar os significados atribuídos por pacientes portadores do vírus da hepatite $\mathrm{C}$ sobre a doença e o tratamento dietético. Para tanto, adotase a metodologia da pesquisa qualitativa em que o sujeito interage com sua narrativa sobre o objeto de estudo e os pesquisadores analisam cuidadosamente seus enunciados. As acepçôes sobre o adoecer e as mudanças dos hábitos alimentares e de vida dos pacientes foram analisadas por meio da obtenção de entrevistas em profundidade. Ao trazer os sentidos expressos sobre a doença, cria-se a possibilidade de compreensão dos aspectos culturais sobre a alimentação, a nutrição e a dietética; um desafio para os profissionais de saúde e nutrição, que precisam relatar a seus pacientes a necessidade de seguir hábitos alimentares mais saudáveis, implicando alterações nem sempre simples de serem realizadas. Consideram-se hábitos e representações do ato da alimentação, como parte da identidade cultural do sujeito. Justifica-se este estudo pela necessidade de situar maior interação entre profissionais, estudantes de saúde e pacientes de modo a ampliar a compreensão dos fenômenos que cercam a experiência $\mathrm{da}$ doença pelos pacientes. Conclui-se que os pacientes de hepatite $\mathrm{C}$ atendidos no ambulatório do Hospital Universitário da cidade de Salvador e o profissional podem atingir os objetivos de aconselhamentos nutricionais, se trilharem direções dialógicas. Com isso, observou-se a adesão à orientação dietética sem rupturas bruscas e sofrimentos dos pacientes.

> Palavras-chave: vírus Hepatite C; pesquisa qualitativa; hábitos alimentares.
1 Nutricionista; pós-graduanda do Programa de Residência em Nutrição Clínica pela UFBA. Endereço eletrônico: carlinhaufba@yahoo.com.br

${ }^{2}$ Nutricionista; doutora em Ciências de Saúde (FM-

USP); professora adjunta da ENUFBA; coordenadora da Residência em Nutrição clínica (SESAB). Endereço eletrônico: rosangelamazza@yahoo.com.br

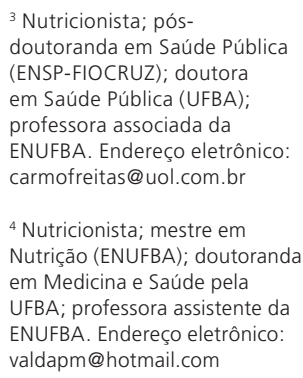

${ }^{4}$ Nutricionista; mestre em Nutrição (ENUFBA); doutoranda em Medicina e Saúde pela UFBA; professora assistente da ENUFBA. Endereço eletrônico: valdapm@hotmail.com

Recebido em: 09/06/2010. Aprovado em: 01/06/2011. 
A trajetória da hepatite $\mathrm{C}$ na saúde pública teve início a partir da notificação em 1975, com a transfusão sanguínea como causada por um vírus desconhecido, não permitindo a instituição de medidas preventivas para tal doença (BASTOS, 2007). Somente em 1989, foi realizado o isolamento e identificação o agente causal da hepatite $\mathrm{C}$, sendo as medidas de rastreamento de estoques de sangue iniciadas no ano seguinte (WHO, 2002). Neste intervalo, permaneceu uma disseminação silenciosa, que se revelaria mais tarde um problema de saúde pública em todo o mundo.

A principal forma de contágio se dá por via parenteral, mas a infecção ocorre também por outros meios, como compartilhamento de materiais perfurocortantes, como agulhas, lâminas de barbear, instrumentos de manicure etc. (BRASIL/MS, 2007). Associado a este fato, é importante destacar que os sinais e sintomas provenientes da doença se manifestam de forma muito lenta, podendo demorar até mais de duas décadas para serem percebidos. Isto torna ainda mais difícil a profilaxia individual para evitar a transmissão, já que o indivíduo não tem conhecimento de que é portador do vírus e mantém atitudes que perpetuam a transmissão (BRASIL/MS, 2007; BASTOS, 2007).

Após ter o diagnóstico da doença, a qualidade de vida do paciente sofre influência de fatores físicos, biológicos, sociais, psicológicos e culturais. $\mathrm{O}$ cotidiano passa a ser controlado em função das restrições impostas pela doença, interferindo nas suas atividades e relações sociais (TRENTINI et al., 2006). Uma maneira de se ter acesso às experiências de conviver com a doença é a análise da fala do paciente, que possibilita um entendimento em maior profundidade da realidade vivida pelo mesmo.

O diálogo entre o profissional de saúde e o paciente é um campo importante de estudo que permite uma melhoria do cuidado com as doenças, em especial as doenças crônicas como a hepatite por vírus C. Porém, durante a interação simbólica entre paciente e profissional de saúde, é perceptível uma abordagem semiótica inadequada. Já que esta é normalmente guiada pela perspectiva do profissional, sendo excluída ou diminuída a perspectiva do doente, sua experiência do adoecer e, em consequência, suas narrativas (LIRA; CATRIB; NATIONS, 2003). Assim, perde-se a essência da interação, que é a percepção e a atuação diante do fenômeno do adoecimento humano. Esta interação facilita a intervenção na 
vida cotidiana dos pacientes e na sua experiência com os fenômenos da saúde e da doença, refletindo em uma assistência individualizada e que promove efeitos positivos na qualidade de vida do paciente.

Para que haja melhor relação entre o profissional e o paciente, é importante a dedicação de um tempo de consulta para que seja possível a troca de experiências. Nesta perspectiva, observou-se que alguns pacientes encontram o espaço que necessitavam para conversar, tirar as dúvidas sobre a doença, e até mesmo confidenciar suas angústias. Quando o profissional associa o fornecimento de informaçôes ao processo de ouvir e compreender a realidade vivida pelo paciente há uma maior eficiência do atendimento nutricional. Deste modo, cria-se um ambiente de diálogo e aprendizado mútuo, em que o fornecimento de orientações se adéqua ao contexto socioeconômico e emocional do paciente, propiciando adesão ao tratamento nutricional e assiduidade às consultas.

Este trabalho tem como objetivo investigar os significados atribuídos por pacientes sobre a hepatite $\mathrm{C}$ pelos próprios pacientes Nesse sentido, são valorizados seus enunciados sobre o diagnóstico e as modificações dietéticas associadas à hepatite, durante o atendimento ambulatorial realizado no Hospital Universitário da cidade de Salvador-BA.

\section{Metodologia}

Para a elaboração deste trabalho, optou-se por realizar uma pesquisa qualitativa, por se tratar de uma abordagem capaz de valorizar as acepções do paciente sobre sua doença e tratamento dietético. Apresenta-se a hepatite como um fenômeno que é clínico, conforme descrição da biomedicina, mas também possui aspectos da cultura, conforme expresso pelos pacientes atendidos no ambulatório do hospital referido. Foram realizadas entrevistas e feitas interpretaçōes de suas narrativas sobre as experiências vividas com a hepatite C. Fundamentalmente, buscou-se interpretar os significados atribuídos ao fenômeno estudado (a experiência da hepatite $\mathrm{C}$ pelos pacientes) e à trajetória terapêutica.

Teoricamente, trata-se de apreender a experiência do sujeito e sua doença no mundo cotidiano. Para tanto, valoriza-se o paciente como sujeito da ação e compreendem-se, a partir de seus enunciados, suas vivências sobre a doença; os sintomas, os medos, estigmas que sentem no meio social ao se revelar enfermo. O ponto principal da análise é o conjunto de sensações vivenciadas no mundo 
cotidiano; o mundo do sentido comum atribuído pelos pacientes, em que o campo da ação social se inscreve com a subjetividade e gera a possibilidade de compreender a ação do outro, ou seja, o entendimento da intersubjetividade da experiência da doença e seu tratamento (SCHUTZ, 1979; MINAYO, 1994).

O trabalho foi dividido em três etapas: 1) Descrição: resulta da relação dos sujeitos com o pesquisador para a obtenção dos primeiros diálogos guiados por um roteiro de questôes; 2) Redução e aprofundamento: o segundo momento da trajetória tem como objetivo determinar e selecionar as partes do diálogo que são consideradas essenciais para compreender o fenômeno; 3) Compreensão: ocorre quando as narrativas individuais dos pacientes (das entrevistas transcritas) são analisadas, considerando os termos analíticos ou significantes que aparecem em relevo nesses textos.

\section{A região de inquérito sobre a doença hepatite $C$}

A pesquisa foi realizada no Ambulatório de Nutrição e Hepatologia, pertencente ao prédio de ambulatórios Prof. Magalhães Neto, anexo ao complexo Hospitalar Universitário Professor Edgar Santos, na cidade do Salvador-BA. O estudo mostra a importância conferida ao atendimento prestado no referido ambulatório pelos pacientes portadores do vírus da hepatite $\mathrm{C}$ (VHC), que estavam realizando ou não tratamento medicamentoso e que eram encaminhados por hepatologistas deste serviço. Os participantes do estudo são sujeitos que vivenciam o fenômeno, e são pacientes que estão sob acompanhamento nutricional no ambulatório, excluindo-se os de primeira consulta.

\section{A obtenção das narrativas}

Para a coleta de informações, aqui atribuídos como expressōes narrativas, as pesquisadoras entraram em contato com os pacientes portadores do VHC acompanhados pelo ambulatório e que já tinham recebido pelo menos um atendimento nutricional. Foi considerado o interesse dos mesmos em participar voluntariamente do estudo, sendo garantido o anonimato quanto à participação e manutenção da assistência nutricional, mesmo se houvesse desistência em participar do estudo.

Com as entrevistas em profundidade, a partir de um roteiro mínimo de questôes, respeitou-se o silêncio sobre perguntas não desejadas. As descriçõos espontâneas dos sujeitos foram imprescindíveis para a compreensão das suas 
percepções. As entrevistas foram realizadas com o auxílio de um gravador e transcritas em sua totalidade, para análise de seu conteúdo.

O número de participantes não foi estabelecido inicialmente, pois segundo o método adotado, a análise das descrições foi sendo realizada até o momento em que a essência do fenômeno investigado fosse percebida e as respostas encontrassem certa saturação (MINAYO; SANCHES, 1993). Dessa forma, realizaram-se entrevistas com oito sujeitos, cujas narrativas foram trabalhadas minunciosamente. A coleta de dados ocorreu no período de setembro a dezembro de 2008, e teve início após a autorização do Comitê de Ética em Pesquisa da Escola de Nutrição da Universidade Federal da Bahia. Foi solicitada ao paciente sua autorização para a gravação de suas falas sobre a doença, após a assinatura do termo de consentimento livre e esclarecido. Para assegurar o anonimato, os nomes dos participantes foram substituídos por nomes fictícios.

\section{Análise das narrativas}

$\mathrm{O}$ trabalho do pesquisador é a análise das narrativas dos pacientes, que revelam significados referentes à hepatite $\mathrm{C}$ na condição situacional da realidade do sujeito. Isto não se reduz a reescrever e a reconstruir o texto do paciente, mas a conceber conexões entre os termos e sentenças que mais se destacam nas narrativas (RICOEUR, 1989). Os múltiplos sentidos observados sobre sintomas e sinais podem ser contraditórios e similares.

Inicialmente, as narrativas foram numeradas e transcritas sem qualquer interpretação do seu conteúdo. Com as leituras posteriores, foi-se buscando em cada narrativa os termos e sentenças que deram significados ao atendimento e à doença. Por meio desta reflexão, conformou-se uma rede de associações entre os estes. $\mathrm{E}$ ao reunir os diversos sentidos sobre a experiência em viver com a hepatite $\mathrm{C}$ e de como se sentem no atendimento ambulatorial, agregou-se a interpretação dos pesquisadores. Com este procedimento metodológico, foi possível revelar sentidos da doença e do tratamento dietético-clínico pelos pacientes.

\section{Resultados e discussão}

Nas ciências da saúde, o processo da comunicação é de extrema relevância. Infelizmente, este instrumento básico da terapêutica recebeu menor atenção ao longo do desenvolvimento dos profissionais, restringindo-os ao trabalho mecânico 
e impulsivo do cuidado físico do paciente, diminuindo seu espaço profissional, sua atuação e inibindo uma comunicação efetiva (SILVA; SILVA, 2004).

Por meio do relato dos pacientes, foi possível caracterizar a prática social, experiências e aflições do grupo que compartilha semelhantes realidades: ser portador do vírus da hepatite C-VHC, pertencer às camadas populares de Salvador, ser atendido no mesmo ambulatório. Assim, numa entrevista podem sobressair valores individuais, definições e atitudes do grupo ao qual o indivíduo pertence. Desta maneira, foi possível buscar semelhanças das experiências entre os sujeitos estudados, permitindo a elaboração de novas narrativas que representaram a experiência de viver uma doença crônica (SPINDOLA; SANTOS, 2003; MINCIS; MINCIS, 2004).

Para os pacientes com doença hepática crônica que não apresentaram sintomas por longo tempo, o diagnóstico da infecção ocorre muitas vezes em função de exames laboratoriais de rotina, em que são observadas alterações da função hepática (BASTOS, 2007). A partir desta suspeita, exames mais específicos são solicitados, como o anticorpo contra o vírus da hepatite C ou ANTI-HCV e HCV-RNA, que detecta a presença e a quantidade de vírus, respectivamente (WHO, 2002). A biópsia hepática é então solicitada para a confirmação da hepatite crônica, verificação do grau de necrose e fibrose, para estadiamento, identificação da evolução da doença e decisão terapêutica para o paciente (MUÑOZ, 2003).

A busca por um profissional de saúde pode ocorrer no intuito de resolver, aparentemente, um simples mal-estar ou algum sintoma tipicamente "normal" que vem gerando desconforto, como no caso de Maurício:

Foi no fim de 2006. Um exame de rotina, um check-up de fim de ano. Eu queria saber por que estava tendo muita ressaca e fiz outros exames. Com o exame de sangue, o médico mandou em procurar o gastro-hepatologista porque viu alteração. Justamente, ele confirmou (Maurício).

Ao descobrir-se doente, surgem inúmeras questōes que desestruturam a vida do indivíduo, ocasionando um turbilhão de emoçôes que giram em torno do medo ao desconhecido (a doença) e incertezas em relação ao seu futuro. Em outro caso, a descoberta da doença provoca alívio:

Fiquei sabendo em 1998 que era portadora, através de exames. Tudo que eu comia me fazia mal. Eles (os médicos) se reuniram para ver realmente o que é que eu tinha, pediram o exame de hepatite e deu. Eu melhorei muito, só de saber o que é que eu tinha (Ana-grifo nosso). 
Uma das grandes preocupações dos pacientes está relacionada ao sofrimento causado por temer a perda de sua autonomia, devido às consequências à saúde trazidas pela enfermidade. Eles não querem perder a independência e a rede social. Para tanto, a tristeza e a ansiedade constituem respostas aos sentimentos em relação à doença, devido aos potenciais de riscos à vida do paciente (MARTINS; FRANÇA; KIMURA, 1996). Isto pode ser observado na narrativa da paciente: "É muito triste. A gente se sente mal de ter a doença" (Emília).

Outro fator que merece destaque, dentre os sentimentos que o paciente descreve, é o medo da exclusão, de sofrer o preconceito ou perder as suas relações sociais. Este é o caso de Edna, que mesmo recebendo o diagnóstico da doença silenciou. "Eu penso que essa doença é contagiosa, não sei, pode evitar a amizade que eu tenho com as pessoas e pode me excluir" (Edna).

O fornecimento do diagnóstico de uma doença crônica implica mudanças muito significantes na vida do paciente. Normalmente, a conduta do médico é de suma importância para a explicação deste diagnóstico, e quais as interferências da doença na rotina do portador. A equipe de saúde, nestes casos, atua como uma rede de apoio que deve estar mobilizada para preparar e acompanhar este paciente em sua nova etapa: o convívio com a doença (FONTANELLA; CAMPOS; RIBEIRO, 2006).

$\mathrm{Na}$ realidade cotidiana de uma pessoa com doença crônica, ocorre uma limitação do seu espaço às atividades diárias, em decorrência da necessidade de mudar o estilo de vida, bem como o hábito alimentar. Essas situações podem implicar ausência a eventos sociais para evitar a ingestão de alimentos inadequados, ou para que as pessoas o enxerguem na condição de doente. Assim, a condição crônica de saúde pode levar a diversas perdas para os relacionamentos sociais, nas atividades de lazer e de prazer conduzindo o paciente ao comprometimento da qualidade de vida e a rever os seus conceitos de vida e cultura (BRITO, 2008).

A compreensão dos aspectos culturais sobre alimentação e nutrição constitui uma produção de saberes para profissionais de saúde e nutrição, que precisam orientar seus pacientes sobre a necessidade de mudança dos seus hábitos. As sensações habituais e a inscrição de novas, a partir da orientação dietética, implicam alterações nem sempre simples de serem realizadas pelos pacientes em seu mundo cotidiano (FREITAS; PENA, 2007). As referências são outras e a complexidade de aceitação de uma alimentação considerada saudável pelo 
nutricionista, nem sempre pode ser adquirida imediatamente pelo paciente.

As orientações nutricionais fornecidas durante a consulta no ambulatório servem de base para que o paciente siga dicas para o seguimento de uma alimentação mais condizente com a realidade dele. De modo individual, as orientações norteiam as escolhas alimentares referentes à sua condição de saúde. Este procedimento possibilita a avaliação em consultas subsequentes para avaliar a adaptação do paciente ao que lhe foi proposto pelo nutricionista. Esta atitude permite que as orientações sejam readaptadas às condiçôes socioeconômicas e culturais do paciente e reesclarecidas a sua importância, de modo a torná-las mais fáceis de serem adotadas. No entanto, este não é um procedimento simples, já que os pacientes têm suas dificuldades e não as admitem pelo receio que sentem da coerção do profissional. Muitos relatos referem à ausência de diálogo e também ao prosseguimento de orientações recebidas:

A depender da alimentação eu melhorei muito. Continuo comendo um pouco de gordura, bem pouco, porque eu já não estou gorda, e se eu não comer nenhuma gordura fico driblando as regras (Ana).

Sempre escapa alguma coisa. Por mais que você queira, às vezes uma pessoa que diz que está fazendo tudo certo, está mentindo, na medida do possível eu sigo (Maurício).

Eu como [comida baiana, frituras] de vez em quando, assim, às vezes, mas demora. Às vezes não compro [os alimentos orientados] porque fico enjoada de comer direto aquilo, sempre a mesma coisa (Camila).

Quando eu quero, faço tudo certinho, quando eu não quero dou uma escapulida (Edna).

Escapulir, driblar e mentir aparecem nessas falas como se fossem estratégias de fuga. Fuga das orientações cansativas por terem sempre os mesmos alimentos, devido ao pouco recurso financeiro que possuem ou porque estas orientações dietéticas não agregam prazer à vida destes pacientes. Ao contrário, estas orientações se não estiverem bem aclaradas aprisionam ainda mais o paciente. Dessa forma, não basta possuir o conhecimento, é preciso levá-lo ao nível da análise crítica do próprio hábito e das representações relativas ao ato da alimentação. O hábito alimentar, como parte do habitus, é compreendido na dimensão do cotidiano, em que a experiência faz parte da identidade cultural do sujeito (FREITAS; PENA, 2007; SETTON, 2002).

Uma nova orientação pedagógica alimentar pode envolver o conceito de alimentação saudável, que contemple e interprete os significados das escolhas alimentares dos sujeitos, respeitando suas próprias organizações sociais, que 
produzem e reproduzem valores sobre o corpo e a vida. Para a compreensão da realidade, é de fundamental importância se familiarizar e conhecer como o indivíduo produz os seus símbolos e sentidos. Isto pode ser realizado por meio de associações que guardam autonomia com a conduta alimentar e a história social (FREITAS; PENA, 2007; BOOG, 1999).

Algumas doenças, em especial este trabalho, a hepatite $\mathrm{C}$ exige mudanças alimentares habituais, que permitem reduzir a progressão da doença, retardando os efeitos danosos do vírus $\mathrm{C}$ ao organismo e aparecimento dos sintomas. Estas mudanças não são tão restritivas, mas devem contemplar uma alimentação saudável, equilibrada, e com um fracionamento e volume adequados. Entretanto, em alguns casos após a verificação da alimentação habitual do indivíduo, faz-se necessário dialogar sobre uma restrição alimentar, já que a dieta é um fator determinante na regulação da ingestão. O comportamento restritivo passa a ser compreendido como o resultado da interação entre fatores fisiológicos, na origem do desejo de comida (apetite), e esforços cognitivos para resistir a este desejo (VIANA, 2002).

Esta restrição é de difícil aceitação, está associada à dificuldade para o seguimento, principalmente no início da mudança alimentar. Maria e Lúcio relatam esta dificuldade atribuída ao hábito de ingerir um volume aumentado, e ter de se adaptar a uma ingestão alimentar mais reduzida.

Logo no início eu sentia que era como se não estivesse me satisfazendo, depois acostumei, foi o período de adaptação, porque eu como muito (Maria).

No início a gente sente. Depois passa a ser educado. Recebe as orientaçôes. Mas isso é para quem quer, pois quem não quer continua a ser guloso (Lúcio).

A ideia crítica de uma ingestão exagerada, por parte dos pacientes, deve ser o alvo de trabalho para os profissionais de saúde, pois, como dito anteriormente, o tratamento dietoterápico dos pacientes com doença hepática crônica tem por base restrições alimentares. Estas podem ser difíceis de adaptação, mas devem ser encaradas como um desafio a ser vencido, tendo como resultado final a melhora da sintomatologia da doença, e a prevenção do surgimento de outras patologias como esteatose hepática, diabetes e hipertensão arterial, em especial para àqueles com excesso de peso.

Assim, é de extrema importância que o profissional fique atento a este tipo de comportamento, e que enfoque o seu trabalho no diálogo e contexto social específico de cada caso, apresentando pequenas atitudes a cada consulta. Isto 
deve ocorrer de forma lenta e gradual, incentivando passo a passo as conquistas do paciente a cada dia, mudando sua percepção e hábito alimentar. É uma caminhada compreensiva junto ao paciente, com conversas sobre sentidos objetivos e subjetivos do tratamento. Este, cauteloso na conduta entre profissional e paciente que caminham juntos para à redução do risco. No sentido, contrário, quando as orientações são exigidas de uma só vez e criticadas pelo profissional de saúde, notou-se a regressão ao tratamento.

A presença do nutricionista comprometido e capacitado sobre a terapia nutricional e o processo de adoecimento pode ser essencial para o sucesso da terapia nutricional. Isso pode se refletir na preocupação com o paciente, na qualificação do cuidado recebido, na possibilidade de os pacientes falarem sobre aspectos não só relacionados à doença, mas a seus problemas, ansiedade $\mathrm{e}$ frustrações vivenciadas no cotidiano, bem como nas dificuldades enfrentadas em relação à doença e ao tratamento. A atuação profissional também pode significar o recebimento de orientações que favoreçam o desenvolvimento do autocuidado, apontando para uma visão mais crítica sobre seus direitos nos serviços de saúde (COSTA; ALVES; LUNARDI, 2006; VEIROS, 2002).

A maneira como o profissional se aproxima do paciente e de sua doença como um processo natural conforta-o e possibilita o diálogo. Como exemplo, cita-se o caso da paciente Maria, a qual relata sentir-se melhor pelo tratamento que recebe, pois passou a superar o preconceito e aceitar a Hepatite C.

Eu sou bem tratada. Isso ajuda muito as pessoas que tem esse tipo de doença e não tem esclarecimento. Hoje eu tenho esclarecimento, aqui também eles tratam a gente muito bem, não tem discriminação com nada. Eu estou tranquila, não tenho mais problema (Maria).

Quando se é tratado com indiferença, o paciente sofre. O tratamento com diálogo e analisando os significados de suas falas, pelos profissionais, acaba confortando o paciente e criando uma relação afetiva entre ambos, que pode durar muito tempo. Desta forma, a relação possibilita um trabalho mais digno e de compreensão mútua.

Os resultados apresentados trazem a importância do diálogo nas intervenções nutricionais. Isto se dá com a análise interpretativa dos sentidos e significados obtidos nas narrativas dos pacientes. Os termos analíticos a partir de certas palavras e sentenças denunciam sensibilidade do paciente sobre sua doença e aspectos do universo simbólico, como por exemplo: "comendo um pouco de 
gordura" ou" driblando as regras", ou "enjoada de comer direto aquilo, sempre

a mesma coisa", são algumas das semelhanças encontradas em relação à rejeição da alimentação normativa. Todas essas respostas mostram a identidade cultural do paciente com suas representações da doença e do tratamento dietético; hábitos e práticas alimentares.

Uma ferramenta importante para auxiliar o nutricionista no processo de melhora da qualidade da dieta é a educação nutricional, com o fim primordial de fornecer os conhecimentos necessários e a motivação coletiva para formar atitudes e hábitos de uma alimentação saudável, completa, adequada e variada. $\mathrm{O}$ papel da educação em alimentação e nutrição está vinculado à produção de informações que sirvam como subsídios para auxiliar a tomada de decisões dos indivíduos que são ignorantes neste aspecto, tornando-se agora capazes de ampliar o seu poder de escolha e decisão diante dos seus problemas de saúde (VEIROS, 2002; BOOG, 1999).

Nesse contexto de educação, Paulo Freire (2005) propóe que a atitude do educador não deve apenas falar da realidade como algo distante das experiências dos educandos, mas estimulá-los a interagir nesse processo. Um conceito que pode ser aplicado na prática clínica. Esta concepção de educação, quando aplicada aos pacientes, permite que eles se tornem sujeitos ativos do processo que estão vivendo, participando de forma reflexiva e crítica da construção de novos hábitos alimentares, dentro de sua realidade.

Trabalhar as atitudes dos pacientes a fim de torná-los críticos em relação a suas próprias atitudes é necessário para se obter resultados em situaçôes-problema, como pacientes que possuem doenças crônicas. Estes pacientes necessitam se conscientizar primeiro da sua condição de doente, sobre os mecanismos da sua doença e posteriormente sobre a interferência da sua alimentação na evolução da doença que o acometeu (BOOG, 1999).

O papel da nutrição, personificada pelo nutricionista, pode ser observado ao longo das falas que são apresentadas a seguir. Ao atingir a satisfação, bem estar e em alguns casos tornar o paciente confiante sobre a sua vida, sobre a possibilidade de melhorar, torna gratificante o atendimento prestado. Mesmo poucas horas destinadas ao paciente podem surtir efeitos na forma como eles vivem e como se alimentam, e podem influenciar beneficamente a evolução clínica. Este período de dedicação pode se tornar precioso, pelo valor e influência que trazem e podem 
mudar a perspectiva de alguém, que até pouco tempo não sabia para onde ir ou o que fazer para melhorar sua saúde e melhorar a sua vida.

Se não fosse a nutrição não resolveria muito. É fundamental a nutrição, ela me tratou muito bem. Principalmente para o pessoal que está em tratamento (Lúcio).

A partir da dieta que eu recebi me senti mais leve, porque eu ficava com o estômago muito cheio e enjoava. Eu comecei agora e estou comendo outras coisas, comer sólido que eu não comia de jeito nenhum agora como duas vezes na semana. Estou tentando seguir, estou confiante pra ver se eu recupero o meu peso, eu dependo de vocês! (Ana).

Eu estou me sentindo mais forte agora depois que comecei a fazer dieta. É importante, principalmente por causa do peso que eu estava perdendo, agora estou me sentindo melhor (Camila).

No processo de convivência com pacientes com doença crônica, o profissional de nutrição passa a ser uma referência para eles. Trata-se da possibilidade de diálogo, conversação, ou da necessidade de alguém que escute o que sente, suas expectativas e medos, nesta fase de recuperação da doença. Alguém que passa saberes e apreende outros, que demonstra abertura para a escuta da linguagem do sujeito, dialogando maneiras de ele se sentir melhor com o alimento.

Quando a fala e a escuta são valorizados, ambos envolvidos aprendem. O paciente com toda sua história e experiência de vida traz ao profissional novas reflexôes sobre suas atitudes e torna possível o aprimoramento do seu atendimento. Ao se sensibilizar com a história do paciente que está na sua frente, o profissional passa a agir de forma diferente dos modelos teóricos de procedimento e conduta de atendimento. Isso se deve por transcender o caráter histórico-cultural implícito no paradigma biomédico, evocando em si o desejo de cuidar em que predomina a sensibilidade de uma nutrição compreensiva para a análise textual da linguagem do paciente (FOUCAULT, 2004; FREITAS, 2008).

\section{Conclusão}

Os profissionais e estudantes de saúde, ao trabalharem com seres humanos, necessitam se desvincular do modelo tecnicista-científico e ampliar a compreensão dos fenômenos que cercam a vida e a doença, que são vivenciados e simbolizados por seus pacientes. A partir do conhecimento destes fenômenos, os profissionais percebem que seus pacientes detêm experiências de vida e informações específicas que lhes ajudarão a compreender profundamente os vários problemas de saúde e de vida por eles, apresentados. 
Quando se conhece mais sobre a realidade do paciente, torna-se possível se aproximar das necessidades deste indivíduo. Torna-se possível, ainda, que as orientações fornecidas por um nutricionista, por exemplo, sejam adequadas à rotina do paciente.

Este estudo mostra que as mudanças na vida do paciente portador da hepatite C incluem hábitos alimentares e estilo de vida mais saudáveis que podem ser conquistados no processo dialógico entre paciente e nutricionista.

Essas orientações devem ser explicadas claramente e detalhadas para cada paciente, como forma de fazê-lo refletir a importância de sua participação como construtor de novos hábitos. A maneira mais eficaz de se realizar uma boa adesão e seguimento das orientações ocorre com a compreensão da realidade vivida pelo paciente. Nesse aspecto, esta pesquisa qualitativa na obtenção de informações consistiu em um instrumento que trouxe novas noções sobre as experiências dos pacientes.

O nutricionista, portanto, deve compreender os significados atribuídos pelo paciente sobre sua doença, e obter elementos necessários para facilitar o manejo nutricional e saber por onde iniciar mudanças dietéticas, estas que devem ser graduais e no tempo adequado, para promover a adesão pelo paciente.

\section{Referências}

BARTHES, Roland. Elementos de semiologia. São Paulo: Pensamento-Cultrix, 2004. 116 p. BASTOS, F.I. O som do silêncio da hepatite C. Rio de Janeiro: Fiocruz, 2007. 100p.

BOOG, M.C.F. Dificuldades encontradas por médicos e enfermeiros na abordagem de problemas alimentares. Revista de Nutrição, Campinas, v. 12, n. 3, p. 261-272, 1999.

BOOG, M.C.F. Educação nutricional em serviços públicos de saúde. Cadernos de Saúde Pública, Rio de Janeiro, v. 15, n. 2, p. 139-147, 1999.

BRASIL. Ministério da Saúde. Hepatite C que doença é essa? Informaçōes básicas e dúvidas frequentes. Cartilha elaborada pelo Grupo Vontade de Viver, Salvador, 2007. 18 p.

BRITO, D.M.S. de. Qualidade de vida e percepção da doença entre portadores de hipertensão arterial. Cadernos de Saúde Pública, Rio de Janeiro, v.24, n.4, p.933-940, 2008. COSTA, V.T.; ALVES, P.C.; LUNARDI, V.L. Vivendo uma doença crônica e falando sobre ser cuidado. Revista de Enfermagem da UERJ, Rio de Janeiro, v. 14, n. 1, p. 27-31, 2006.

FONTANELLA, B.J.B.; CAMPOS, C.J.G.; RIBEIRO, E. Coleta de dados na pesquisa clínico-qualitativa: uso de entrevistas não-dirigidas de questôes abertas por profissionais da saúde. Revista Latino-Americana de Enfermagem, Ribeirão Preto, v. 14, n. 5, p. 812-820, 2006. 
FOUCAULT, M. O nascimento da clínica. Rio de Janeiro: Forense Universitária, 2004. 231 p. FREIRE, P. Pedagogia do oprimido. São Paulo: Paz e Terra, 2005. 213 p.

FREITAS, M.C.S. de. Educação nutricional e alimentar algumas considerações sobre o discurso. In: FREITAS, MCS; FONTES, GAV; OLIVEIRA, N. Escritas e narrativas sobre alimentação e cultura. Salvador: EDUFBA, 2008. p. 305-311.

FREITAS, M.C.S.; PENA, P.G.L. Segurança alimentar e nutricional: a produção do conhecimento com ênfase nos aspectos da cultura. Revista de Nutrição, Campinas, v. 20, n. 1, p. 69-81, 2007.

LIRA, G.V.; CATRIB, A.M. F.; NATIONS, M.K. A narrativa na pesquisa social em saúde: perspectiva e método. Revista Saúde, Fortaleza, v. 16, n. 2, p. 59-66, 2003.

MARTINS, L.M.; FRANÇA, A.P D.; KIMURA, M. Qualidade de vida de pessoas com doenças crônicas. Revista Latino-Americana de Enfermagem, Ribeirão Preto, v. 4, n. 3, p. 5-18, 1996.

MINAYO, M.C.S. Desafio do conhecimento: pesquisa qualitativa em saúde. São Paulo: Hucitec, 1994.

MINAYO, M.C.S.; SANCHEZ O. Quantitativo e qualitativo: oposição e complementaridade? Cadernos de Saúde Pública, v. 9, n. 3, p. 237-248, 1993.

MINCIS, R.; MINCIS, M. Hepatite C: avanços no diagnóstico e tratamento. Revista Einstein, São Paulo, v. 2, n. 4, p. 343-345, 2004.

MUÑOZ, L.A. et al. Significados simbólicos de los pacientes con enfermedades crônicas. Revista da Escola de Enfermagem da USP, São Paulo, v. 37, n. 4, p. 77-84, 2003.

RICOEUR, P. Do texto à ação. Lisboa: Rés, 1989.

SCHUTZ, A. Fenomenologia e relaçôes sociais. Rio de Janeiro: Zahar, 1979.

SETTON, M. da G.J. A Teoria do habitus em Pierre Bourdieu. Revista Brasileira de Educação, Rio de Janeiro, v. 24, n. 20, p. 60-70, 2002.

SILVA, M.F. da; SILVA, M.J.P. da, A autoestima e o não-verbal dos pacientes com queimaduras. Revista da Escola de Enfermagem da USP, São Paulo, v. 38, n. 2, p. 206-216, 2004.

SPINDOLA, T.; SANTOS, R. da S. Trabalhando com História de Vida: os percalços de uma pesquisa(dora?). Revista da Escola de Enfermagem da USP, São Paulo, v. 37, n. 2, p. 119-126, 2003.

TRENTINI, M. et al. Qualidade de vida de pessoas dependentes de hemodiálise considerando alguns aspectos físicos, sociais e emocionais. Texto e Contexto em Enfermagem, Santa Catarina, v. 13, n. 1, p. 74-82, 2006. 
VEIROS, M.B. Análise das condiçôes de trabalho do nutricionista na atuação como promotor de saúde em uma unidade de alimentação e nutrição: um estudo de caso. 2002. 211p. Dissertação (Mestrado em Engenharia de Produção) - Programa de pós-graduação em Engenharia de Produção/Ergonomia, Universidade Federal de Santa Catarina, Florianópolis, 2002.

VIANA, V. Psicologia, saúde e nutrição: contributo para o estudo do comportamento alimentar. Análise Psicológica, Lisboa, v. 4, n. 20, p. 611-624, 2002.

WORLD HEATH ORGANIZATION. Hepatitis C. Geneva, 2002. 69 p. 


\section{Reflections about getting sick and dietetic changes during nutritional assistance with hepatitis $C$ patients}

This paper investigates the meanings attributed by patients to hepatitis $\mathrm{C}$ on disease and dietary treatment. To this end, we adopt the methodology of qualitative research in which the individual interacts with his narrative on the subject of study and the researchers carefully examine their statements. The meanings of the illness and changes in dietary habits and life of the patients were analyzed by obtaining in-depth interviews. By bringing the senses expressed about the disease, it creates the possibility of understanding cultural factors on diet, nutrition and dietetics - a challenge for health professionals and nutrition, which need to report their patients the need to follow dietary healthier, involving changes not always simple to perform. Habits and representations of the act of feeding are considered part of the cultural identity of the subject. This study is justified by the need to place greater interaction among professionals, students, patients and health so as to broaden the understanding of the phenomena that surround the experience of illness by patients. We conclude that outpatients with hepatitis $\mathrm{C}$ at the University Hospital in the city of Salvador and the professional can achieve the goals of nutritional advice, if they follow dialogic lines. Thus, there was compliance with dietary counseling without sudden breaks and suffering of patients.

> Key words: Hepatitis C virus; quality study; feeding habits. 